\title{
Efficacy of autologous platelet-rich plasma in the treatment of chronic nonhealing leg ulcers
}

\section{Shwetha Suryanarayan ${ }^{1}$, Leelavathy Budamakuntla ${ }^{1}$, Syed Iqbalulla Sha Khadri², Sacchidanand Sarvajnamurthy ${ }^{1}$}

${ }^{1}$ Department of Dermatology, STD and Leprosy, Bangalore Medical College and Research Institute, Bengaluru 560001, Karnataka, India. ${ }^{2}$ Department of General Surgery, Bowring and Lady Curzon Hospital, Bangalore Medical College and Research Institute, Bengaluru 560001, Karnataka, India.

Address for correspondence: Dr. Shwetha Suryanarayan, Department of Dermatology, STD and Leprosy, Bowring and Lady Curzon Hospital, OPD No. 22, Shivajinagar, Bengaluru 560001, Karnataka, India. E-mail: shwetha.215@gmail.com

\begin{abstract}
Aim: The aim was to evaluate the efficacy of platelet-rich plasma (PRP) in the treatment of chronic nonhealing ulcers. Methods: A nonrandomized, uncontrolled study was performed on 24 patients with 33 nonhealing ulcers of various etiologies. All patients were treated with PRP at weekly intervals for a maximum of 6 treatments. At the end of the 6-week period, reduction in size of the ulcers (area and volume) was assessed. Results: The mean age of the patients was 42.5 years (standard deviation [SD] 12.48). Of 33 ulcers, there were 19 venous ulcers, 7 traumatic ulcers, 2 ulcers secondary to pyoderma gangrenosum, 2 diabetic ulcers, 2 trophic ulcers, and 1 vasculitic ulcer. The mean duration of healing of the ulcers was 5.6 weeks (SD 3.23). The mean percentage of reduction in area and volume of the ulcers was $91.7 \%$ (SD 18.4\%) and 95\% (SD 14\%), respectively. About 100\% resolution in the area was seen in $25(76 \%)$ of the ulcers and $100 \%$ reduction in volume was seen in $24(73 \%)$ of the ulcers at the end of the 6th treatment. Conclusion: Conventional therapies do not provide satisfactory healing for chronic nonhealing ulcers as they are not able to provide the necessary growth factors (GFs) (platelet-derived GF, epidermal GF, vascular endothelial GF, etc.) which are essential for the healing process. PRP is a safe, affordable, biocompatible, and simple office-based procedure for the treatment of nonhealing ulcers.
\end{abstract}

Key words:

Leg ulcers, platelet-derived growth factor, platelet rich plasma

\section{INTRODUCTION}

Chronic nonhealing leg ulcer is defined as the "loss of skin and subcutaneous tissue on the leg or foot, which takes more than 6 weeks to heal". Chronic ulceration of the lower leg, including the foot, is a frequent condition, causing pain, social discomfort, and generating

\begin{tabular}{|l|l|}
\hline \multicolumn{2}{|c|}{ Access this article online } \\
\hline Quick Response Code: & Website: \\
\hline & www.parjournal.net \\
\cline { 2 - 2 } & \\
\hline
\end{tabular}

considerable costs. ${ }^{[1]}$ The prevalence of leg ulcers is well documented to be vary between $0.18 \%$ and $1 \%{ }^{[2]}$ The three major causes of lower extremity ulcers are venous, arterial, and neuropathic.

Chronic nonhealing ulcers lack the necessary growth factors (GFs) and hence do not heal well. Conventional recombinant GF products, including becaplermin (recombinant platelet-derived GF) have been approved by the Food and Drug Administration for the treatment of chronic wounds. However, the medication is in a liquid form, and, therefore, easily dissipates following wound application. In addition, it is expensive and is unaffordable in developing countries such as India. ${ }^{[3]}$

Platelet-rich plasma (PRP) enhances wound healing through promotion of the healing process by the presence 
of which are important in modulating mesenchymal cell recruitment, proliferation, and extracellular matrix synthesis during the healing process. ${ }^{[4]}$ Autologous PRP is a safe, easy, and cost-effective method with good results in the management of chronic nonhealing ulcers. PRP has been a breakthrough in the stimulation and acceleration of bone and soft tissue healing. It represents a relatively new biotechnology that is part of the growing interest in tissue engineering and cellular therapy today.

\section{METHODS}

The aim of this study was to evaluate the efficacy of PRP in the management of chronic leg ulcers. This was a nonrandomized, uncontrolled study conducted from January 2011 to September 2012 at a tertiary hospital in Bengaluru. Ethical clearance was obtained before beginning of the study from Ethical Clearance Committee. A total of 24 patients with 33 nonhealing ulcers of various etiologies were included in this study. Inclusion criteria were ulcers of more than 6 weeks duration. Patients with a bleeding disorder, uncontrolled sugar levels and ulcers with active infection and saphenofemoral junction incompetency were excluded. Detailed history including the name, age, sex, address, contact number, occupation, and history of medication was noted. Patients were thoroughly examined and ulcer size (length, breadth, and width) was measured by the "clock-face" method described by Sussman using a cotton tip applicator and ruler.

Under aseptic precautions, $20 \mathrm{~mL}$ of venous blood was drawn and added to a test tube containing acid citrate dextrose in a ratio of 9:1 (blood: acid citrate dextrose). It was centrifuged at $5000 \mathrm{rpm}$ for $15 \mathrm{~min}$ to separate the red blood cells from platelet and plasma. ${ }^{|5|}$ The lower part of the plasma was then collected and centrifuged again at $2000 \mathrm{rpm}$ for $5 \mathrm{~min}$. The bottom layer of about $1.5 \mathrm{~mL}$ was harvested, and $10 \%$ calcium chloride was added to activate PRP $\left(0.3 \mathrm{~mL}\right.$ for $1 \mathrm{~mL}$ of PRP). ${ }^{[6]}$ Activated PRP was applied onto the wound after proper surgical debridement and was dressed in a nonabsorbent dressing. After activating PRP with calcium chloride, it should be applied immediately onto the wound as $70 \%$ of GFs are released within ten minutes and 90\% within one hour. Hence, we should activate PRP just before use, rather than in advance, to avoid losing GFs. Because PRP can synthesize additional amounts of GF for about 8 days until depletion, PRP application was repeated weekly. After 1 week, the dressing was removed with normal saline and assessed for improvement. The procedure was repeated once weekly for 6 weeks. Wound area was calculated using the formula for an ellipse: length $\times$ width $\times 0.7854$ (an ellipse is closer to a wound shape than a square or rectangle that would be described by simple length $\times$ width). The use of an ellipse for calculating wound measurement has been used in randomized controlled trials in wound healing literature. ${ }^{[7]}$ Volume was calculated using the formula (length $\times$ width $\times 0.7854) \times$ depth.

The treatment outcome was defined as a percentage improvement in area and volume of the ulcer.

\section{RESULTS}

Twenty-four patients with 33 nonhealing ulcers of various etiologies were treated with PRP at weekly intervals for a maximum of 6 treatments. The mean age of the patients was 42.5 years (standard deviation [SD] 12.48) [Table 1]. Of 33 ulcers, there were $19(57.75 \%)$ venous ulcers, 7 (21.2\%) traumatic ulcers, $2(6 \%)$ pyoderma gangrenosum ulcers, $2(6 \%)$ diabetic ulcers, $2(6 \%)$ trophic ulcers, and $1(3 \%)$ vasculitic ulcer [Figure 1]. The duration of the ulcers ranged from 2 months to 1 year with a mean of 4.75 months [Table 2]. The mean duration of healing of the ulcers was 5.6 weeks (SD 3.23). The baseline mean area and volume of the ulcer was $10.93 \mathrm{~cm}^{2}$ (SD 7.791) and $5.1 \mathrm{~cm}^{3}$ (SD 4.3). The final mean area and volume of the ulcer at the end of 6 weeks were $1.3 \mathrm{~cm}^{2}$ (SD 2.72) and $0.4 \mathrm{~cm}^{3}$ (SD 1.27). The declining trend in the reduction of sum of the area and volume of the ulcers is shown [Figures 2 and 3]. The mean percentage of improvement in area and volume of the ulcers was $91.7 \%$ (SD 18.4\%) and 95\% (SD 14\%), respectively [Tables 3 and 4]. The confidence interval is been shown in Table 5. $P$ value was set at less than 0.05 and hence the results were found to be significant. About $100 \%$ improvement in the area was seen in $25(76 \%)$ of the ulcers and 100\% improvement in volume was seen in $24(73 \%)$ of the ulcers at the end of the 6th treatment [Figures 4 and 5]. There were no side effects noted. The before and after PRP therapy photographs are shown [Figures 6-11]. We also noted that there was a

\section{Table 1: Age distribution}

\begin{tabular}{lcc}
\hline Age group (years) & Number of patients & Percentage \\
\hline$<20$ & 0 & 0 \\
$21-30$ & 7 & 29 \\
$31-40$ & 3 & 12.5 \\
$41-50$ & 5 & 21 \\
$51-60$ & 9 & 37.5 \\
$>60$ & 0 & 0 \\
Total & 24 & 100 \\
\hline
\end{tabular}

Table 2: Duration of the ulcer

\begin{tabular}{lcc}
\hline $\begin{array}{l}\text { Duration of the } \\
\text { ulcer (months) }\end{array}$ & Number of ulcers & Percentage \\
\hline$<3$ & 6 & 18 \\
$3-6$ & 21 & 64 \\
$6-9$ & 3 & 9 \\
$9-12$ & 3 & 9 \\
Total & 33 & 100 \\
\hline
\end{tabular}

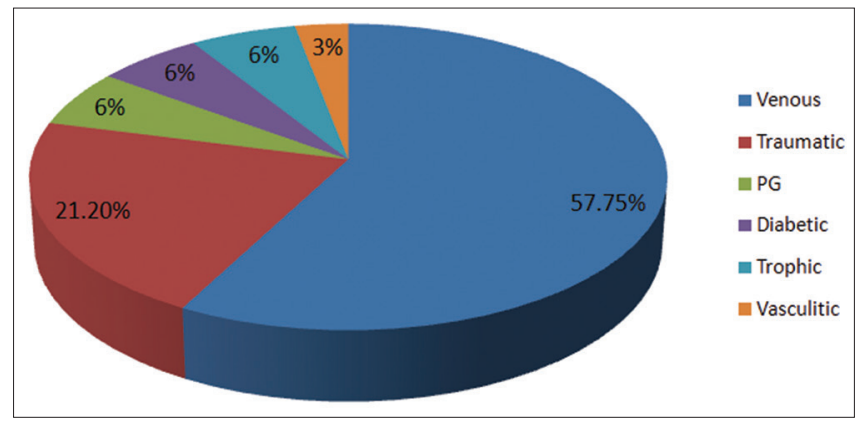

Figure 1: Various causes of ulcer. PG: pyoderma gangrenosum 


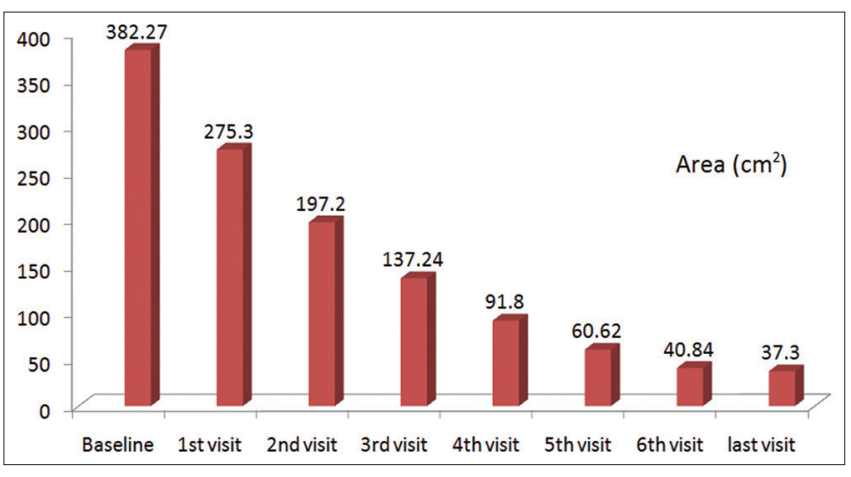

Figure 2: The sum of the mean area of the ulcers from baseline to last visit

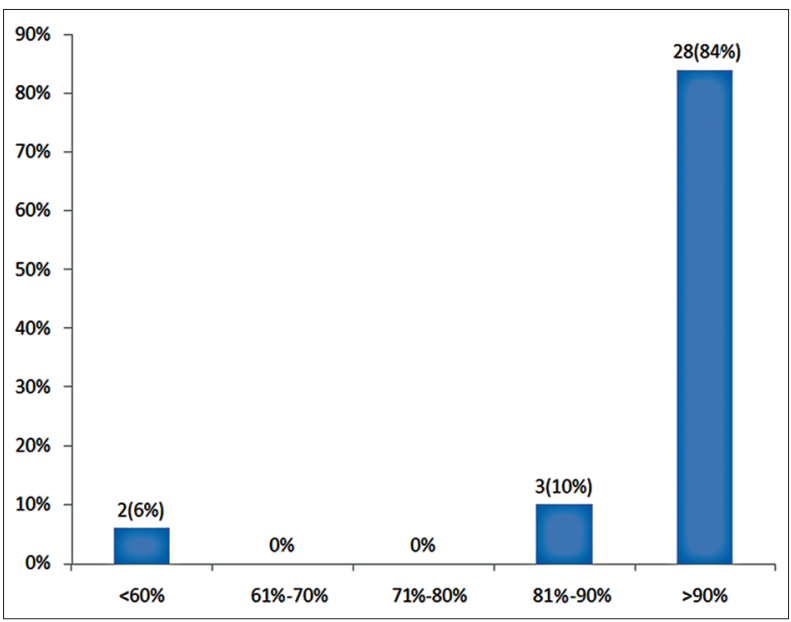

Figure 4: Percentage improvement in area of the ulcers

Table 3: Improvement of area of the ulcer in percentage at the end of 6th sitting

\begin{tabular}{lcc}
\hline $\begin{array}{l}\text { Percentage improvement in } \\
\text { area at the end of 6th sitting }\end{array}$ & $\begin{array}{c}\text { Number } \\
\text { of ulcers }\end{array}$ & Percentage \\
\hline$<60$ & 3 & 10 \\
$61-70$ & 0 & 0 \\
$71-80$ & 4 & 12 \\
$81-90$ & 0 & 0 \\
$91-100$ & 26 & 78 \\
\hline
\end{tabular}

Table 4: Improvement of volume in percentage at the end of 6 th sitting

\begin{tabular}{lcc}
$\begin{array}{l}\text { Percentage improvement in } \\
\text { volume at the end of 6th sitting }\end{array}$ & $\begin{array}{c}\text { Number } \\
\text { of ulcers }\end{array}$ & Percentage \\
\hline$<60$ & 2 & 6 \\
$61-70$ & 0 & 0 \\
$71-80$ & 0 & 0 \\
$81-90$ & 3 & 10 \\
$91-100$ & 28 & 84 \\
\hline
\end{tabular}

reduction in pain and discharge within 1 week due to the anti-inflammatory property of PRP, which contains leukocytes. There were no side effects reported.

\section{DISCUSSION}

Chronic wounds come with cost and morbidity for patients and society. These wounds are found in all types

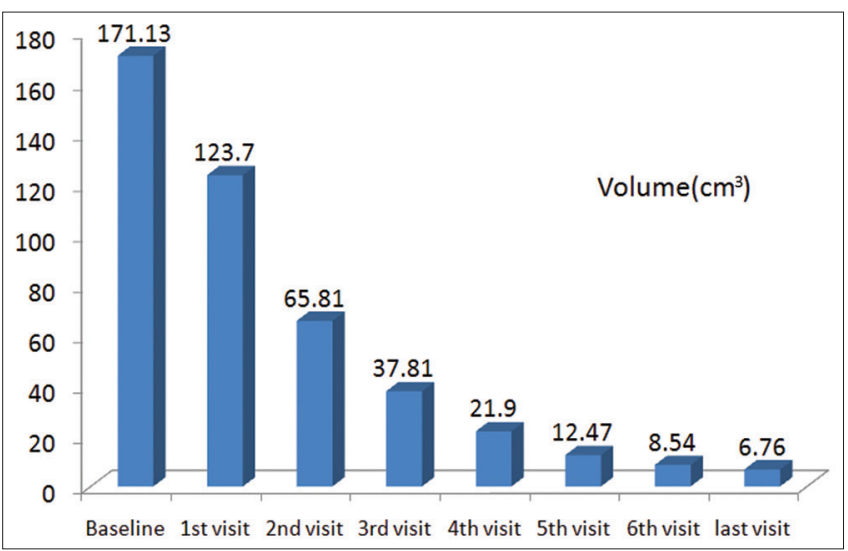

Figure 3: The sum of the mean volume of ulcers from baseline to last visit

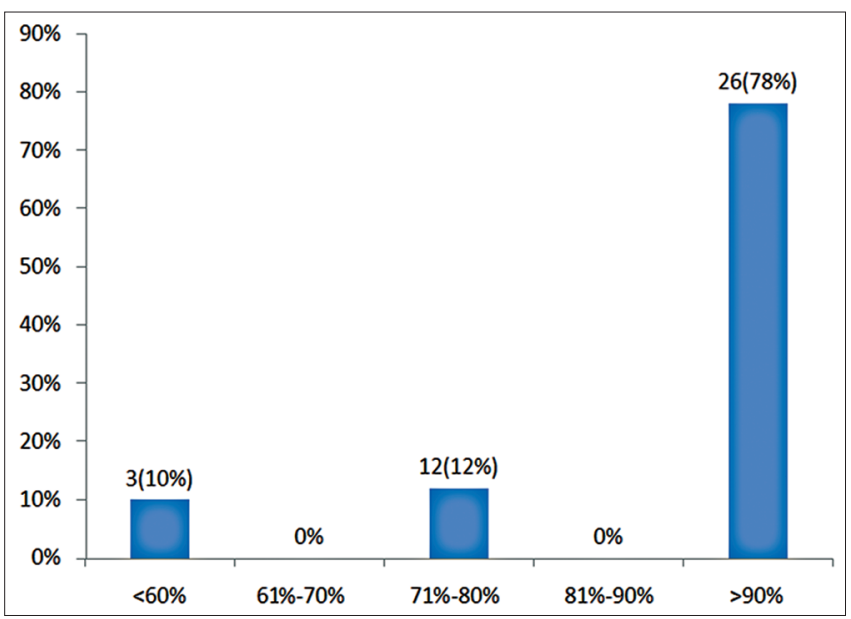

Figure 5: Percentage improvement in volume of the ulcers

of healthcare settings and are a challenge for healthcare providers. Chronic nonhealing ulcers are often difficult to treat. Conventional therapies such as dressings, surgical debridement, and even skin grafting cannot provide satisfactory healing since these treatments are not able to provide the necessary GFs to modulate the healing process. $^{[8]}$

In 1986, Knighton et al. ${ }^{[9]}$ showed that the accelerated epithelialization of granulation tissue leading to complete repair of chronic nonhealing ulcers is attainable by the use of autologous platelet factors. This was the first clinical demonstration that locally acting factors derived from autologous blood promote healing of chronic cutaneous ulcers. In this study, the time to $100 \%$ healing after initiation of platelet-derived wound-healing factors (PDWHF) was $7.5 \pm 6.5$ weeks. There was a direct correlation between the initiation of PDWHF therapy and $100 \%$ healing. The age of the patients and the location of the ulcers had no statistically significant effect on PDWHF-stimulated wound repair.

Platelet-rich plasma enhances wound healing by promoting the healing process secondary to its GFs. These include platelet-derived GF $(\alpha \alpha, \beta \beta$, and $\alpha \beta)$, fibroblast GF, vascular endothelial GF, epidermal GF, insulin-like GF, and transforming GF. These GFs stimulate 
Table 5: $\mathrm{Cl}$ and $P$ value which suggests that results were significant

\begin{tabular}{lcccccccc}
\hline & Baseline & 1st visit & 2nd visit & 3rd visit & 4th visit & 5th visit & 6th visit & Final visit \\
\hline Area & 10.98 & 8.42 & 6.24 & 4.57 & 3.06 & 2.02 & 1.36 & 1.13 \\
$P$ value & & 0.1706 & 0.0125 & 0.0004 & $<0.0001$ & $<0.0001$ & $<0.0001$ & $<0.0001$ \\
$\mathrm{Cl}$ & & $-1.11-6.14$ & $1.05-8.33$ & $2.95-9.76$ & $4.71-11.03$ & $5.88-11.94$ & $6.59-12.55$ & $6.93-12.76$ \\
Volume & 5.19 & 3.53 & 2.19 & 1.26 & 0.73 & 0.42 & 0.23 & 0.39 \\
$P$ value & & 0.1160 & 0.0020 & $<0.0001$ & $<0.0001$ & $<0.0001$ & $<0.0001$ & $<0.0001$ \\
$\mathrm{Cl}$ & & $-0.42-3.74$ & $1.14-4.84$ & $2.23-5.62$ & $2.83-6.08$ & $3.18-6.36$ & $3.38-6.54$ & $3.21-6.38$ \\
\hline
\end{tabular}

$\mathrm{Cl}$ : Confidence interval

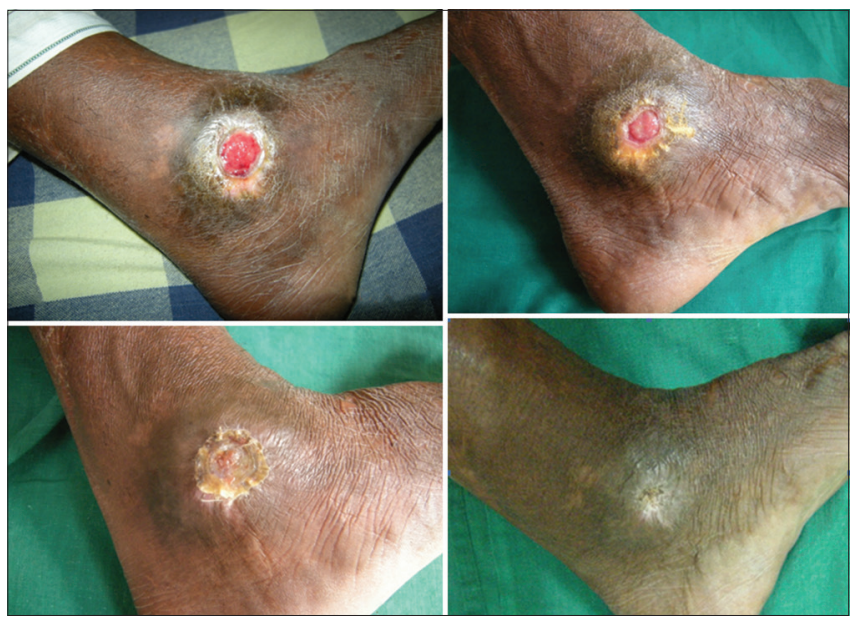

Figure 6: 24 bit (true color) traumatic ulcer of 2 months duration healed after two sittings of platelet rich plasma
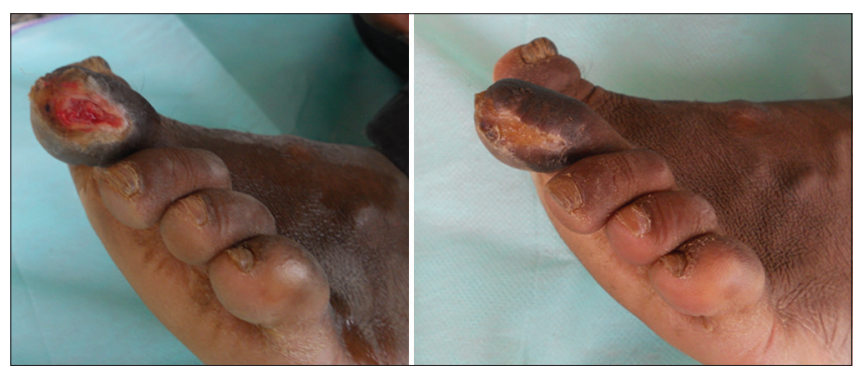

Figure 8: 24 bit (true color) trophic ulcer of 3 months duration healed within 2 weeks
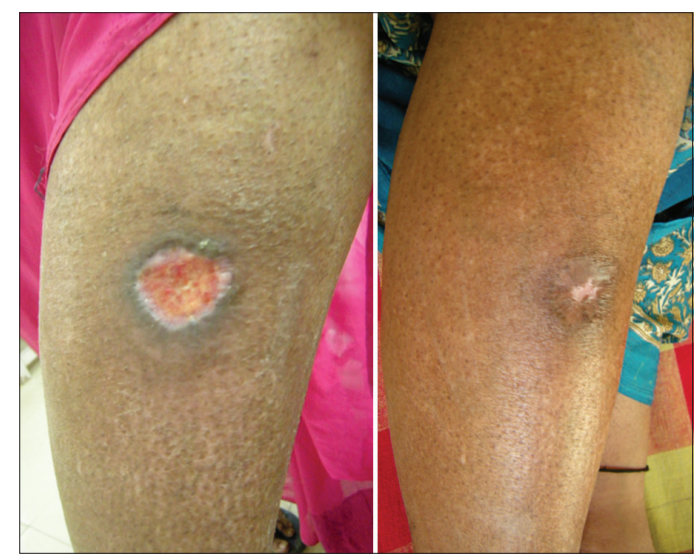

Figure 10: 24 bit (true color) traumatic ulcer healed after one sitting of platelet rich plasma

mesenchymal cell recruitment, proliferation, extracellular matrix degeneration, and cell differentiation for tissue regeneration. These factors are released from $\alpha$ granules

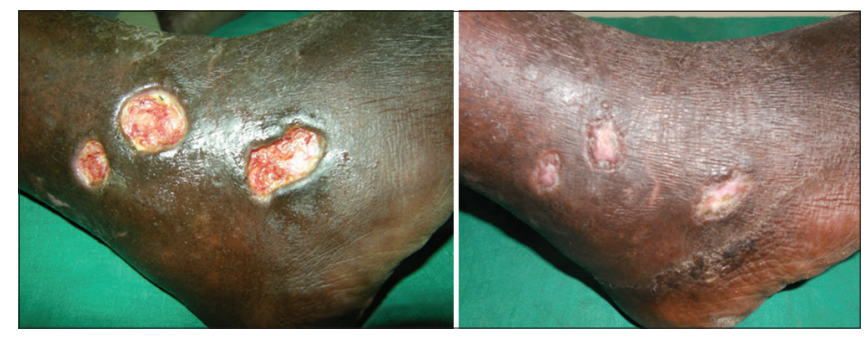

Figure 7: 24 bit (true color) venous ulcer of 6 months duration healed after three sittings of platelet rich plasma
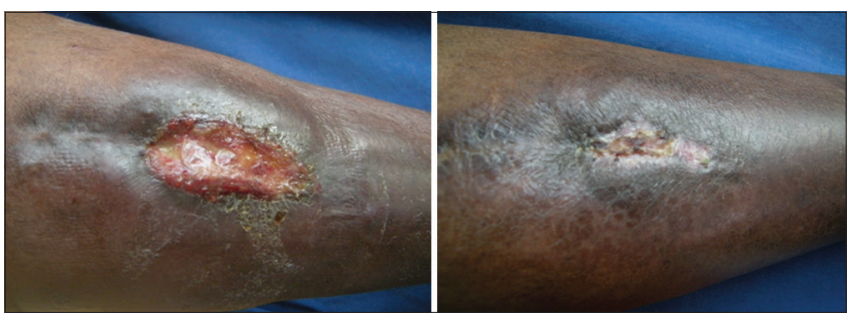

Figure 9: 24 bit (true color) traumatic ulcer of 4 months duration healed after three sittings of platelet rich plasma

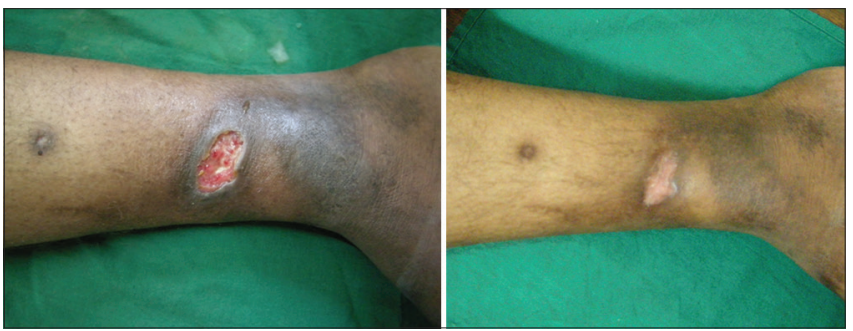

Figure 11: 24 bit (true color) venous ulcer of 7 months duration healed after six sittings of platelet rich plasma

in response to platelet activation by inducers of platelet aggregation. ${ }^{\mid 10]}$

The anti-inflammatory factors in PRP also play a role in wound healing because of the presence of leukocytes, which are at high levels in PRP. ${ }^{[8]}$

In addition to the GFs, platelets release numerous other substances (e.g. fibronectin, vitronectin, and sphingosine 1-phosphate) that are important in wound healing. An advantage of PRP over the use of single recombinant human GF delivery is the release of multiple GFs and differentiation of factors upon platelet activation. ${ }^{[11]}$

There is no standard method of preparation of PRP in literature. According to Marx, to truly concentrate platelets from autologous blood, the device must use 
a double centrifugation technique. ${ }^{[12]}$ Regardless of the rate of centrifugation or the time of centrifugation, a single spin cannot adequately concentrate platelets, because the red blood cells will interfere with their fine separation. ${ }^{[4]}$

A study conducted by Frykberg et al. ${ }^{[13]}$ on 49 patients with 65 nonhealing ulcers showed that 63 of 65 ulcers responded with a reduction in area, volume and undermining of the ulcers in a mean duration of 2.8 weeks with 3.2 treatments.

Steenvoorde et al. ${ }^{[14]}$ conducted a study on 12 patients with 13 wounds, showing that 7 of 13 wounds required more than 1 application, with a mean number of 2.2 applications and a mean treatment period of 4.2 weeks.

Kakudo et al. ${ }^{[15]}$ treated five cases of intractable skin ulcer with autologous PRP, among which three ulcers healed completely within 4 weeks and epithelization of wound occurred within 6.6 weeks on average.

In our study, 24 patients with 33 ulcers were treated with PRP and the mean duration of healing of the ulcers was 5.6 weeks (SD 3.23). We also noticed a decrease in pain.

Chronic wounds are a frequent problem in developing countries. Because these wounds lack the necessary GFs for healing, they are often difficult to heal and are frequently complicated by superinfection. PRP contains various GFs that are necessary in wound healing. In addition, the high concentration of leukocytes present in PRP is also helpful in preventing infections. ${ }^{[16]}$

Currently, there is a paucity of critical scientific data regarding the beneficial effects of PRP in clinical procedures. In the current study, PRP was found to be useful in treating chronic leg ulcers. However, further controlled, randomized prospective clinical trials are necessary to definitively demonstrate its efficacy. There is also a need for the development of a standard protocol for the preparation of PRP, as literature currently there is no standardization of the procedure.

\section{REFERENCES}

I. Mekkes JR, Loots MA, Van Der Wal AC, Bos JD. Causes, investigation and treatment of leg ulceration. Br J Dermatol 2003; I48:388-40I.

2. Anderson I. Aetiology, assessment and management of leg ulcers. Wound Essent 2006;1:20-36.

3. Braund R, Hook S, Medlicott NJ. The role of topical growth factors in chronic wounds. Curr Drug Deliv 2007;4:195-204.

4. Bhanot S, Alex JC. Current applications of platelet gels in facial plastic surgery. Facial Plast Surg 2002; 18:27-33.

5. Vaishnavi C, Mohan B, Narayanan LL. Treatment of endodontically induced periapical lesions using hydroxyapatite, platelet-rich plasma, and a combination of both: an in vivo study. J Conserv Dent 20I I; |4:I40-6.

6. Sarvajnamurthy S, Suryanarayan S, Budamakuntala L, Suresh DH. Autologous platelet rich plasma in chronic venous ulcers: study of 17 cases. J Cutan Aesthet Surg 2013;6:97-9.

7. Blume PA, Walters J, Payne W, Ayala J, Lantis J. Comparison of negative pressure wound therapy using vacuum-assisted closure with advanced moist wound therapy in the treatment of diabetic foot ulcers: a multicenter randomized controlled trial. Diabetes Care 2008;31:631-6.

8. Yuan T, Zhang CQ, Tang MJ, Guo SC, Zeng BF. Autologous platelet rich plasma enhances wound healing in chronic wounds. Wounds 2009;21:280-5.

9. Knighton DR, Ciresi KF, Fiegel VD, Austin LL, Butler EL. Classification and treatment of chronic nonhealing wounds. Successful treatment with autologous platelet-derived wound healing factors (PDWHF). Ann Surg 1986;204:322-30.

10. Kakudo N, Kushida S, Minakata T, Suzuki K, Kusumoto K. Platelet-rich plasma promotes epithelialization and angiogenesis in a splitthickness skin graft donor site. Med Mol Morphol 201 I;44:233-6.

II. Sánchez AR, Sheridan PJ, Kupp LI. Is platelet-rich plasma the perfect enhancement factor? A current review. Int J Oral Maxillofac Implants 2003; 18:93-103.

12. Marx RE. Platelet-rich plasma (PRP): what is PRP and what is not PRP? Implant Dent 200I;10:225-8.

13. Frykberg RG, Driver VR, Carman D, Lucero B, Borris-Hale C, Fylling CP, RappI LM, Clausen PA. Chronic wounds treated with a physiologically relevant concentration of platelet-rich plasma gel: a prospective case series. Ostomy Wound Manage 2010;56:36-44.

14. Steenvoorde P, van Doorn LP, Naves C, Oskam J. Use of autologous plateletrich fibrin on hard-to-heal wounds. J Wound Care 2008; 17:60-3.

15. Kakudo N, Kushida S, Ogura N, Hara T, Suzuki K. The use of autologous platelet rich plasma in the treatment of intractable skin ulcer. Open J Reg Med 20I2; I:29-32.

16. Dohan DM, Choukroun J, Diss A, Dohan SL, Dohan AJ, Mouhyi J, Gogly B. Platelet-rich fibrin (PRF): a second-generation platelet concentrate. Part III: leucocyte activation: a new feature for platelet concentrates? Oral Surg Oral Med Oral Pathol Oral Radiol Endod 2006; I01:e51-5.

How to cite this article: Suryanarayan S, Budamakuntla L, Khadri SI, Sarvajnamurthy S. Efficacy of autologous platelet-rich plasma in the treatment of chronic nonhealing leg ulcers. Plast Aesthet Res 2014; $1: 65-9$.

Source of Support: Nil, Conflict of Interest: None declared.

Received: 01-04-2014; Accepted: 10-07-2014 